OPEN ACCESS

Edited by:

Leonardo Carlucci,

University of Studies G. d'Annunzio

Chieti and Pescara, Italy

Reviewed by:

George Lazaroiu,

Spiru Haret University, Romania

Vijay Victor,

Christ University, India

*Correspondence:

Kun Chang Lee

kunchanglee@gmail.com

Specialty section:

This article was submitted to

Personality and Social Psychology,

a section of the journal

Frontiers in Psychology

Received: 02 April 2021 Accepted: 06 May 2021

Published: 01 June 2021

Citation:

Jeon HG, Kim C, Lee J and Lee KC (2021) Understanding E-Commerce Consumers' Repeat Purchase Intention: The Role of Trust Transfer and the Moderating Effect of Neuroticism

Front. Psychol. 12:690039 doi: 10.3389/fpsyg.2021.690039

\section{Understanding E-Commerce Consumers' Repeat Purchase Intention: The Role of Trust Transfer and the Moderating Effect of Neuroticism}

\author{
Hyeon Gyu Jeon ${ }^{1}$, Cheong Kim ${ }^{1,2}$, Jungwoo Lee ${ }^{1}$ and Kun Chang Lee ${ }^{1,3 *}$ \\ ${ }^{1}$ SKK Business School, Sungkyunkwan University, Seoul, South Korea, ${ }^{2}$ Economics Department, Airports Council \\ International World, Montreal, QC, Canada, ${ }^{3}$ Department of Health Sciences and Technology, Samsung Advanced Institute \\ for Health Sciences and Technology, Sungkyunkwan University, Seoul, South Korea
}

The dominant position of e-commerce is especially being articulated in the retailing industry once again due to several constraints that the world faces in the COVID-19 pandemic era. In this regard, this study explores the significant role of trust transfer (from offline to online) and the moderating effect of consumers' neurotic traits in the framework of trust-satisfaction-repurchase intention in the e-commerce context based on a survey with 406 Korean e-commerce consumers. Moreover, a prediction-oriented segmentation (POS) technique combined with structural equation models (SEM) was utilized to reveal consumers' probable hidden heterogeneous characteristics. The outcomes of the global model SEM analysis indicate that offline-online trust transference occurs in e-commerce, and the conveyed trust significantly influences satisfaction and consumers' repeat purchase intention through satisfaction. Neuroticism also has significant positive effects on trust transfer in the global model. However, results in three subgroups generated by POS show heterogeneous characteristics that considerably differed from the global model test results. The implications from this study will be beneficial to field practitioners in the e-commerce industry in addressing the importance of trust transfer, negative neurotic traits as well as heterogeneous aspects of consumers.

Keywords: trust transfer, neuroticism, satisfaction, repeat purchase, e-commerce

\section{INTRODUCTION}

The importance of e-commerce has been articulated for decades, along with the dramatic evolution of the internet. Moreover, e-commerce's dominant role in the retailing industry is being reilluminated in the COVID-19 pandemic era, which has substantially changed our everyday lives. This phenomenon brought great success to several online-based retailers (i.e., Amazon and eBay) while brought severe slump to those physical-store-based retailers (i.e., traditional department stores). Of course, most brick and mortars have been tried to transit their primary business channel into the network environment, and many of them successfully settled in the new ecosystem by conducting a multichannel strategy (i.e., Bestbuy and Walmart). In this regard, the uncertainty 
for these retailers would be whether consumers' trust from online shopping experiences remain the same as they originally perceived from offline shopping experiences or not. It is evidently crucial for vendors in e-commerce to sufficiently recognize and focus on trust transfer from offline to online, especially if they have a multichannel business (Lee et al., 2007; Ke et al., 2016). Shoppers usually had experienced purchasing in offline shops where offline trust was developed. Likewise, consumers have a tendency to build online trust during the experience of frequent purchasing in e-commerce (Bock et al., 2012).

The trust-satisfaction-loyalty framework is one of the ways to explain the trust mechanism in the relationship of consumerseller (Shapiro, 1987; Cyr, 2008; Jung et al., 2020). Based on the assumption that consumers' trust transfers from offline to online channels, this approach argues that the greater the consumers' trust, the greater their satisfaction with a transaction and their intention to purchase or repurchase in the vendor's online stores (Chen and Chou, 2012; Javed and Wu, 2020). Thus, e-commerce consumers' decisions could be supported by the loyalty framework.

Many recent studies in the IS field have suggested that consumers' decision-making process is governed strongly by their personality traits, such as neuroticism (Mark and Ganzach, 2014; Sharif et al., 2014; Barnett et al., 2015; Dobre and Milovan-Ciuta, 2015). Neuroticism is related broadly to a general state of negative affect (Doty et al., 2013), and researchers in the psychology associated fields, such as cognitive science and neuroscience, have comprehensively scrutinized (Olvet and Hajcak, 2011; Doty et al., 2013; Aluja et al., 2015). In addition, consumers' negative traits (i.e., neurotic) could positively or negatively influence technology use, including the employ online shopping channels (McElroy et al., 2007; Barnett et al., 2015). Nevertheless, although there are some IS studies on neuroticism's effects (Mark and Ganzach, 2014; Sharif et al., 2014; Barnett et al., 2015; Dobre and Milovan-Ciuta, 2015), not many studies have discovered its role in the context of e-commerce settings (Yin et al., 2014).

Besides, the IS field has recently emphasized the importance of considering unobserved heterogeneity hidden in data samples to eliminate threats to the results' validity and ensure their robustness (Becker et al., 2013; Schröder and Hruschka, 2017). Observed heterogeneity, such as gender, age, and other demographic factors, may be addressed quickly (Shao et al., 2015). In contrast, unobserved heterogeneity is difficult to assess in advance, and, therefore, threatens the results' validity and biases empirical conclusions seriously when it remains unnoticed (Rigdon et al., 2010; Schröder and Hruschka, 2017; Wamba et al., 2017; Kim et al., 2020). In other words, there is a need to ensure the robustness of results by addressing such unobserved heterogeneity with logical and rigorous methods.

Henceforth, we were interested in investigating consumers' unobserved heterogeneous neuroticism on the repurchase decision-making. As far as we have examined, unobserved heterogeneity has not been studied in this context until recently (see Table 1). Considering that consumers these days have various hidden characteristics, although these former studies have revealed potential factors affecting consumers' decisionmaking in general based on the given domains, they might have overlooked the importance of exquisite consumer analysis. From these perspectives, we emphasized more on the hidden characteristics of consumers and tried to classified based on their unobserved heterogeneity in the framework of trustsatisfaction-repurchase intention. To achieve this, we applied a latent segmentation method on the basis of structural models which is called PLS-POS (partial least squares predictionoriented segmentation) combining with a conventional structural equation modeling (PLS-SEM). Eventhough PLS (partial least squares) provides general results of statistical analysis, it does not show the characteristics that act as critical segments (ArenasGaitán et al., 2019). The PLS-POS enables measuring both the segments and parameters of belonging of the observed variables (Becker et al., 2013). By doing so, this paper fills the gap that the previous research failed in exploring the consumers' hidden traits, which might considerably affect their decisionmaking.

The primary objective of this research is in three pillars. Firstly, finding the influence of trust transfer on consumers' repeat purchase intention in e-commerce. Second, identifying neuroticism's moderating effect on offline-online trust transition. Lastly, obtaining implications from the entire dataset analysis as well as segmented dataset analysis, which would produce several heterogeneity groups without a possible bias, to redefine the roles of trust transfer and neuroticism in the trust-satisfactionrepurchase framework.

\section{LITERATURE REVIEW AND HYPOTHESES}

\section{Consumer Trust and Transference}

The proposed research question depends primarily on offlineonline trust transference and, secondarily, on the consumer trustsatisfaction-loyalty framework. Therefore, first, we reviewed the literature on the consequences of trust transition on loyalty because it is, after all, related to consumers' purchase behavior.

The objectification of trust could be a set of particular faith-related with benevolence, ability, and integrity of business partners (Kankanhalli et al., 2005; Chen and Hung, 2010; Chiu et al., 2010; Shiau and Luo, 2012), and is essential to formulate and understand consumer behavior both in online and offline commerce, as people develop trust in business transaction partners. Consumers normally possess confidence in a product from a firm when consumers endorse and trust it (Popescu and Ciurlãu, 2019; Standing et al., 2019). Many empirical researchers have emphasized trust by suggesting the trust-satisfaction-loyalty relation as a conceptual framework in the discussion of consumers' behavior, consumers' satisfaction, and their loyalty to the retailers in the context of purchasing goods (Fang et al., 2011; Chen and Chou, 2012; Hsu et al., 2014; Jeon and Lee, 2016a,b). The consumer loyalty framework in IS research can be briefly described as follows. Consumers with greater trust in sellers are more satisfied with the shopping process (Trivedi and Yadav, 2020). 
A high level of consumer contentment has a distinctively encouraging effect on their loyalty to trusted retailers and effects such behaviors as the purchase or repurchase decisions and intentions (Bhattacherjee, 2001; Liu et al., 2011). This conceptual framework represents consumers' universal patterns of purchase decisions.

The online and offline integrated channels can increase customer satisfaction and loyalty further in either channel through the process referred to as "trust transfer" (Jeon and Lee, 2016a,b). Shifting trust is characterized as a cognitive procedure, which implies reproducing the trust from one reference to another or recognized units to unrecognized units. In particular, consumers' perceived trust can flow between channels such as online-to-offline or offline-to-online. Stewart (2003) established a theory of trust transference in the context of retail trade, and trust transfer can be explained from two perspectives: source and process. For example, trust transfer may occur from traditional government services to e-government (Belanche et al., 2014) or from banks on the street to online banking services (Lee et al., 2007). On the other hand, if firms fail to acquire the trust from consumers, then there might be a possibility that consumers perceive notoriety, which will significantly negatively affect their purchase intention (Bratu, 2019; Jiménez-Castillo and Sánchez-Fernández, 2019). From the perspective of a process, such as communication or cognitive processes, an example of trust transfer might be a situation in which a trusted third party provides a consumer with a favorable recommendation of a bank (Lee et al., 2007). Also, this trust transfer process could be intervened by human agencies, such as marketing practitioners in the field, especially in the design stage of the online channel, which sole computer algorithms cannot replace (Klinger and Svensson, 2018; Mircicã, 2020). In this scenario, they are more likely to trust the bank's online operation (Kim and Prabhakar, 2004). Trust transfer can be highly significant to businesses in which the outcomes eventually are linked with consumers' loyalty through purchase intentions.

The way an organization addresses trust transference between channels is critical, particularly for e-commerce retailers who utilize omnichannel strategy with several revenue-generating channels (Lee et al., 2007), as consumers' trust perception processes in e-commerce differ fundamentally from the process in a purely online or offline retail context. Consumers' trust in retailers' stores over the network also will be at a level similar to that in their offline stores because of their previous purchasing experiences (Bock et al., 2012). Thus, building consumer trust in offline channels can be an effective way for e-commerce vendors to sustain consumer loyalty. Also, firms could enhance consumer loyalty by maximizing the potential benefits and mitigating probable risks that could enhance their satisfaction (Hollowell et al., 2019). Based on this understanding of the consumer trustsatisfaction-loyalty framework and trust transference within the e-commerce context, we proposed the following five research hypotheses:

H1: Offline trust affects online trust positively from the trust transfer perspective.
H2: Offline trust affects satisfaction positively from the consumer loyalty perspective.

H3: Online trust affects satisfaction positively from the consumer loyalty perspective.

H4: Satisfaction affects repurchase intention positively from the consumer loyalty perspective.

\section{Neuroticism as a Source of Observed Heterogeneity}

Yin et al. (2014) analyzed the influence of consumer sentiments on trust. Similarly, it is known well that online reviewers' negative emotions are helpful in making appropriate shopping decisions (Kim and Gupta, 2012). However, these studies did not address the effects of such negative personality traits as neuroticism adequately, particularly in the transfer procedure of trust from the offline channels to the online channels in the context of e-commerce trade.

Personality traits cause each individual to demonstrate different affective responses to the same stimuli (Zabkar et al., 2017). These characteristics cause unusual behaviors that are not observable in others in the same specific situation (Bove and Mitzifiris, 2007). The personality trait of neuroticism is related strongly to adverse emotions such as apprehension and resentment (Doty et al., 2013; Barnett et al., 2015). Neuroticism can be expounded as the level of anxiety, depression, anger, embarrassment, worry, and insecurity (Barnett et al., 2015). It can be measured with the Big-five personality traits questionnaire (Norman, 1963; Digman, 1990; Goldberg, 1990) and has been studied previously (Olvet and Hajcak, 2011; Doty et al., 2013; Aluja et al., 2015). Highly neurotic users have more possibility to become vulnerable to psychopathy, tend to produce poor results in perilous tasks, and do not pursue opportunities to learn new things (Barnett et al., 2015); nonetheless, they may be more creative than the average person (Perkins et al., 2015).

Former literature has reported conflicting results about neuroticism's effect on online shopping (McElroy et al., 2007; Svendsen et al., 2013; Sharif et al., 2014; Barnett et al., 2015; Jeon and Lee, 2016a,b). In the decision-making procedure for purchase, consumers with high neuroticism could be impulsive and buy a specific good without considering brand loyalty (Lin, 2010). On the other hand, they tend to perceive risk or uncertainty more strongly and are more sensitive to product prices during the purchase process (Zabkar et al., 2017). Given that highly neurotic consumers may be risk-averse, pessimistic, slow to adapt to change, very cautious in making purchase decisions, and likely to seek safety, neuroticism can be expected to have a more complex influence on the trust transfer procedures in e-commerce. However, the relation between neuroticism and the use of e-commerce systems has not been identified clearly (Barnett et al., 2015). Further, neuroticism has been considered rare in trust transfer studies to date (see Table 1). Therefore, to investigate its effects on consumers' offline-online trust transfer, we proposed the following hypothesis.

H5: Neuroticism will moderate the process of transferring offline trust to online trust. 
TABLE 1 | Previous research on trust transfer.

\begin{tabular}{|c|c|c|c|}
\hline Author(s) & Domain & Channel & $\begin{array}{l}\text { NP and } \\
\text { UH }\end{array}$ \\
\hline Liu et al., 2018 & $\begin{array}{l}\text { Social media } \\
\text { communities }\end{array}$ & Online & $\mathrm{N} / \mathrm{A}$ \\
\hline Cao et al., 2018 & Mobile payment & Online $\rightarrow$ Mobile & \\
\hline Wu et al., 2016 & Shopping mall & Offline & \\
\hline Zhou, 2016 & Mobile shopping & Online $\rightarrow$ Mobile & \\
\hline Chen et al., 2015 & C2C e-commerce & Online & \\
\hline Chen and Shen, 2015 & Social commerce & Online & \\
\hline Shi and Chow, 2015 & Social commerce & Online & \\
\hline Yang et al., 2015 & Mobile shopping & Online $\rightarrow$ Mobile & \\
\hline Belanche et al., 2014 & Public service & Offline $\rightarrow$ Online & \\
\hline Lee et al., 2014 & Cosmetics retailing & $\begin{array}{l}\text { Online } \rightarrow \text { Online } \\
\text { Online } \rightarrow \text { Offline } \\
\text { Offline } \rightarrow \text { Online }\end{array}$ & \\
\hline Lien et al., 2014 & Healthcare industry & Offline & \\
\hline Wang et al., 2013 & Social commerce & Online $\rightarrow$ Mobile & \\
\hline $\begin{array}{l}\text { Badrinarayanan et al., } \\
2012\end{array}$ & Cultural differences & Offline $\rightarrow$ Online & \\
\hline Bock et al., 2012 & Department stores & Offline $\rightarrow$ Online & \\
\hline Hong and Cho, 2011 & e-Retailers & Online & \\
\hline Lee K.C et al., 2011 & Bookstore retailing & Offline $\rightarrow$ Online & \\
\hline Lee J. et al., 2011 & Online shopping & Online & \\
\hline Lin et al., 2011 & Brokerage services & Online $\rightarrow$ Mobile & \\
\hline Chen et al., 2009 & C2C Online shopping & Online & \\
\hline Yang et al., 2008 & Online retailing & Offline $\rightarrow$ Online & \\
\hline Kuan and Bock, 2007 & Grocery retailing & Offline $\rightarrow$ Online & \\
\hline Lee et al., 2007 & Banking & Offline $\rightarrow$ Online & \\
\hline Lim et al., 2006 & Bookstore & Online & \\
\hline $\begin{array}{l}\text { Kim and Prabhakar, } \\
2004\end{array}$ & Banking & Online & \\
\hline $\begin{array}{l}\text { Pavlou and Gefen, } \\
2004\end{array}$ & Online auction & Online & \\
\hline Stewart, 2003 & Computer retailing & Online & \\
\hline $\begin{array}{l}\text { Doney and Cannon, } \\
1997\end{array}$ & $\begin{array}{l}\text { Manufacturer - } \\
\text { Retailer }\end{array}$ & Online & \\
\hline This study & B2C E-commerce & Offline $\rightarrow$ Online & Yes \\
\hline
\end{tabular}

NP, Negative Personality and UH, Unobserved Heterogeneity.

\section{Issue of Heterogeneity Embedded in the Data Sample}

Researchers often presume completely homogeneous human behavior unconsciously (Liebana-Cabanillas and Alonso-DosSantos, 2017). This impetuous assumption could cause not only errors in the results, but practically unrealistic implications as well (Sarstedt et al., 2009). Errors attributable to data heterogeneity long have been an issue in empirical studies in the social and behavioral sciences (Rust and Verhoef, 2005; Becker et al., 2013) because they imperil the cogency of the results and distort implications (Becker et al., 2013).

The PLS-SEM has been considered an appreciative methodology to rigorously examine research data (Hair et al., 2017). The latent class technique (i.e., POS) helps test the theoretical framework by evaluating the structural model's robustness that meets segmentation requirements. Moreover, this technique uses explanatory variables favorably by grouping individuals according to responses to variables in a proposed research model (Sarstedt et al., 2019).

The issue of data heterogeneity centers on the discovery of unobserved heterogeneity (Hair et al., 2016). Until recently, data heterogeneity analysis has followed conventional approaches, which are limited primarily to observed heterogeneity in the data. Researchers have attempted to discover moderating effects and divide samples into subgroups using a priori or contextual variables of heterogeneity observed typically, such as demographics (gender, age, and ethnicity, etc.), individual propensities (personality traits, neuroticism, etc.), and product attributes (Shao et al., 2015). The problem this approach poses is that it is valid only when the researcher can discern the observed heterogeneous variables. This issue is indispensable because dissimilarities, such as personal traits, among consumers could potentially influence their decisionmaking (Drugău-Constantin, 2019).

In contrast, unobserved heterogeneity can be identified only by statistical methods, not by researcher experience or prediction (Hair et al., 2016). Researchers attempt to identify unobserved heterogeneity within data by comparing the subgroups' differences based on the hidden attributes (Hair et al., 2016). It is suggested that erroneous conclusions might be drawn because of the absence of in-depth consideration of unobserved data heterogeneity, arguing that "There may be significant heterogeneity in the data across unobserved groups, and it can bias parameter estimates, lead to Type I and Type II errors, and result in invalid conclusions" (Becker et al., 2013). Type I errors are attributable to researchers' ignorance of the significant differences in heterogeneous subgroups that lead to overgeneralization of the results of the entire sample. In contrast, Type II errors occur when researchers take insignificant effects without considering reversal influences in the heterogeneity groups (Becker et al., 2013). Because hidden heterogeneous traits have a substantial ability to bias results when it is not discovered, the research might obtain wrong consequences (Rigdon et al., 2010; Schröder and Hruschka, 2017; Wamba et al., 2017; Kim et al., 2020). Hence, unobserved heterogeneity should be considered when researchers perform experiments because identifying it improves the possibility that the study will yield relevant implications and offer adequate information (Becker et al., 2013). However, if unobserved heterogeneity could be detected, it can also be useful from the practical perspective, such as corporations' marketing strategies, as it prevents biases and reveals hidden innate influences (Rigdon et al., 2010).

The argument above denotes that if researchers fail to perform the unobserved heterogeneity check, they can draw a significant number of erroneous conclusions in their studies. Nevertheless, until recently, we could find no trust transfer research that addressed this issue (see Table 1). Therefore, to ensure the robustness of our research results, we examined unobserved data heterogeneity's presence and effects from the perspectives of trust transfer and trust-satisfaction-loyalty. For this purpose, we proposed the following hypothesis.

H6: There is hidden heterogeneity in the frameworks of trust transfer and trust-satisfaction-loyalty in the e-commerce context.

Figure 1 depicts the structural model containing paths representing the six hypotheses above. 


\section{METHODOLOGY}

\section{Sample and Data Collection}

We gathered our dataset by conducting an internet-based survey with 406 consumers (females 52.5\%) of Korean multichannel retailers that operate both online and offline channels. The sample data in the study were obtained by a survey company with a large panel list. Non-probability sampling was used to confirm that the participants had the previous purchasing experiences in both channels of the retailers. The participants were informed that the survey was designed to know the overall trust of consumers toward online and offline retailers.

\section{Measures}

All measurement instruments were employed from the previous literature and validated by a pilot test with 30 samples. Five constructs were utilized, including offline trust, online trust, satisfaction, repurchase intention, and neuroticism. The questionnaire was prepared after the measurement items were corrected and modified based on the pilot results to confirm that all questions were explicit (see Table 2). To examine items, we used the scale of seven-point Likert.

"Offline trust" was adopted from Seppänen et al. (2007), using a second-order construct, covering three dimensions: firms, products, and salespeople. This multi-dimensional construct was chosen because it was more manifest in their aspects, demonstrated discriminant validity, and had reduced collinearity risk (Hair et al., 2016). Company trust is identified as the consumers' belief toward retailers in terms of responsibilities and obligations. Product trust implies the expectations of consumers' that the products and services of the retailers are functionally faithful. Finally, salesperson trust refers to the consumers' beliefs that the salespeople will be faithful to their obligations.

"Online trust" is defined as that online vendors would treat consumers with high honesty. To measure the trust for the online channels, we used the questionnaire from the studies of Odekerken-Schröder et al. (2003) and Teo and Yu (2005).

"Satisfaction" implies consumers' assessment of the extent to which vendors satisfy consumers' needs. For the measurement, we used the questionnaire that Bai et al. (2008) have developed.

"Repurchase intention" in the online channels was assessed using the questionnaire that Bhattacherjee (2001) and Lee (2010) have developed, and "neuroticism" was evaluated using the items from the research of Barnett et al. (2015) and Pervin and John (1999).

\section{Procedure and Statistical Technique}

The model was formulated based on the trust-satisfaction-loyalty framework, assuming that consumers' neuroticism will affect the process of offline-to-online trust transfer (see Figure 1).

We focused first on identifying neuroticism's effects on the relation of the transfer from offline to online trust using the entire dataset (global model). In addition, we attempted to reveal neuroticism's unobserved effects based on three data groups

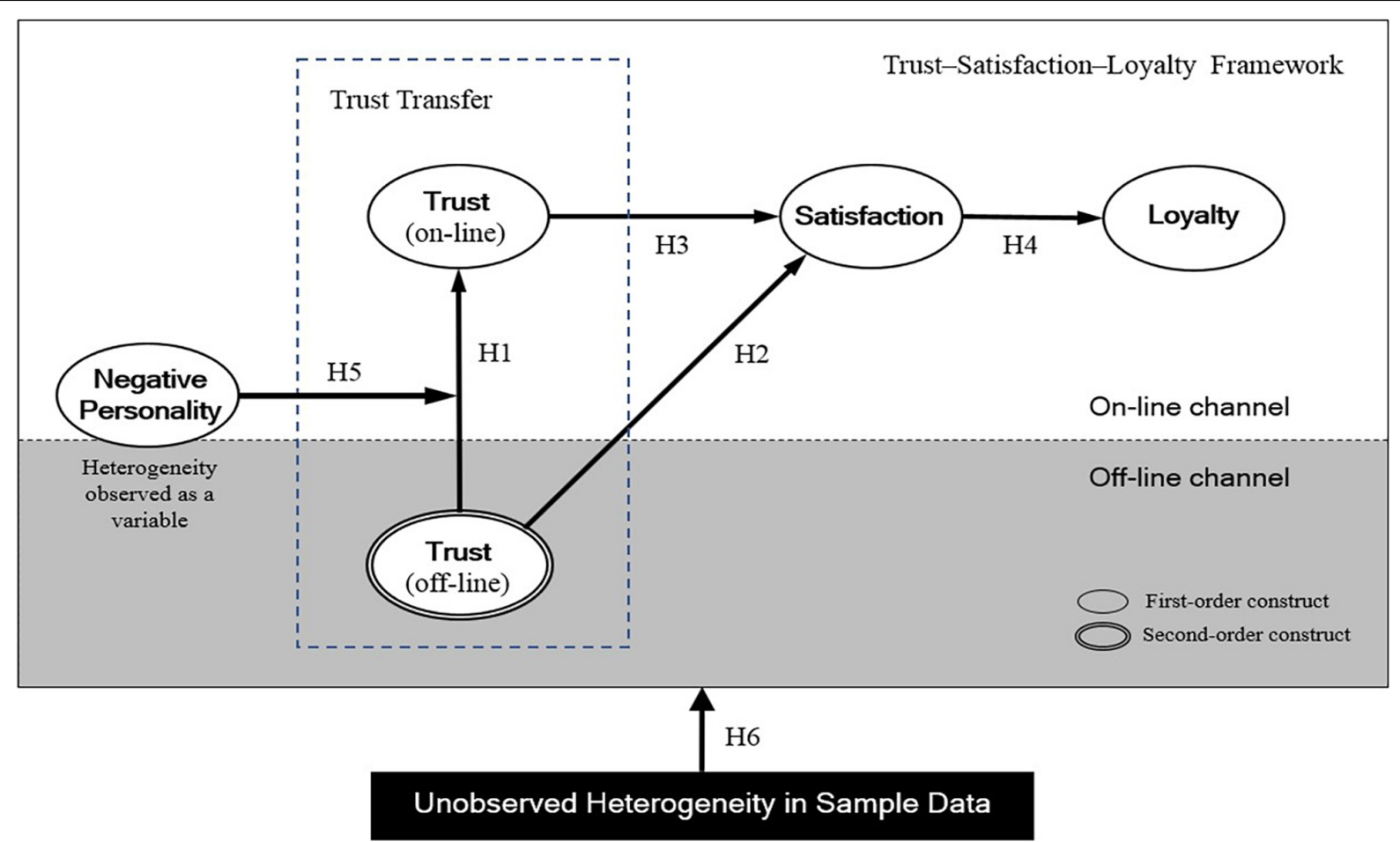

FIGURE 1 | Results of PLS-SEM hypothesis testing on segmented groups according to unobserved heterogeneity (Note: TR, Trust; SA, Satisfaction; RI, Repurchase Intention; and Neuro, Neuroticism). 
TABLE 2 | Research constructs and measurements.

\begin{tabular}{|c|c|c|}
\hline Construct & Item \# & Measurement items \\
\hline \multicolumn{3}{|l|}{ Offline trust (Seppänen et al., 2007) } \\
\hline \multirow[t]{5}{*}{ Company trust } & Comp1 & The company will do what it takes to make us happy. \\
\hline & Comp2 & This salesperson's company has quality people working for them. \\
\hline & Comp3 & The company this salesperson works for will stand behind us. \\
\hline & Comp4 & The company can be counted upon to do right with us. \\
\hline & Comp5 & The salesperson's company has a poor reputation. (reversed) \\
\hline \multirow[t]{4}{*}{ Product trust } & Prod1 & The product will do something we want to do. \\
\hline & Prod2 & The product will not meet our needs without question. (reversed) \\
\hline & Prod3 & The product will please all those who use it or are responsible for it. \\
\hline & Prod4 & This product has the technical attributes necessary to do the job. \\
\hline \multirow[t]{5}{*}{ Salesperson trust } & Sale1 & The salesperson is like a good friend. \\
\hline & Sale2 & When the salesperson tells me something, it must be true. (reversed) \\
\hline & Sale3 & The salesperson did everything possible for us. \\
\hline & Sale4 & The salesperson is not a real expert. (reversed) \\
\hline & Sale5 & The salesperson will always use good judgment. \\
\hline \multirow[t]{3}{*}{ Online trust (Odekerken-Schröder et al., 2003; Teo and Yu, 2005) } & TRon1 & I have trust in this online store. \\
\hline & TRon2 & This online store gives me a trustworthy impression. \\
\hline & TRon3 & This online store gives me a feeling of trust. \\
\hline \multirow[t]{3}{*}{ Satisfaction (Bai et al., 2008) } & SA1 & I am satisfied with my decision to visit this online store. \\
\hline & SA2 & My choice to visit this online store was a wise one. \\
\hline & SA3 & I think I did the right thing by visiting this online store. \\
\hline \multirow[t]{3}{*}{ Repurchase intention (Bhattacherjee, 2001; Lee, 2010) } & $\mathrm{Rl} 1$ & I will frequently use the online store in the future. \\
\hline & $\mathrm{Rl} 2$ & I will use the online store regularly in the future. \\
\hline & $\mathrm{R} / 3$ & I will strongly recommend that others use it. \\
\hline \multirow[t]{4}{*}{ Neuroticism (Pervin and John, 1999; Barnett et al., 2015) } & Neuro1 & I am not easily bothered by things. (reversed) \\
\hline & Neuro2 & I rarely get irritated. (reversed) \\
\hline & Neuro3 & I feel comfortable with myself. (reversed) \\
\hline & Neuro4 & I have frequent mood swings. \\
\hline
\end{tabular}

segmented by the POS method that is an approach to segment data in a non-parametric procedure (Sánchez-Prieto et al., 2017).

\section{RESULTS}

\section{Measurement Model Analysis}

We first examined statistical criteria for the measurement model evaluation, including internal consistency (i.e., Cronbach's $\alpha>0.7$ ), composite reliability (CR $>0.7$ ), convergent validity (i.e., average variance extracted, AVE $>0.5$ ), collinearity diagnosis (i.e., variance inflation factor; VIF $<3.3$ ), and discriminant validity (i.e., Fornell and Larcker criterion and heterotrait-monotrait). Tables 3-6 show that the reliability and validity of the constructs and items have been rigorously confirmed (Carmines and Zeller, 1979; Fornell and Larcker, 1981; Bagozzi and Yi, 1988; Gefen et al., 2000; Straub et al., 2004; Henseler et al., 2015; Hair et al., 2016).

\section{Structural Model Analysis and Hypothesis Tests}

The proposed hypotheses were examined in terms of trust transfer and the consumer loyalty framework (H1 to H4) and neuroticism's moderating effect (H5) based on the measurement model's reliability and validity. The proposed hypotheses were supported statistically when the total number of respondents was used $(n=406)$.

In the trust transfer context, $\mathrm{H} 1$ test found that online trust is statistically positively influenced by offline trust $(\beta=0.35$, $p<0.001)$. This confirms that consumers' offline trust is moved to online. Additionally, the $\mathrm{H} 2$ test showed that offline trust positively and significantly affects online satisfaction $(\beta=0.52$, $p<0.001)$. Thus, offline trust can be a substantial component that affects consumers' decisions in e-commerce.

With respect to the consumer loyalty process in the online context, the $\mathrm{H} 3$ and $\mathrm{H} 4$ tests revealed that online trust has a significantly positive influence on online satisfaction (H3: $\beta=0.13, p<0.01)$, and online satisfaction also have positive relationships with repurchase intention ( $\mathrm{H} 4: \beta=0.70, p<0.001$ ). The results are aligned with many previous studies.

$\mathrm{H} 5$ is to examine whether neuroticism moderates the path between offline trust and online trust or not. To test this hypothesis, we created an interaction construct (offline trust $\mathrm{x}$ neuroticism) by multiplying offline trust (predictor) by neuroticism (moderator) to predict the online trust construct. The estimated coefficient of the moderating effect indicates a significance $(\beta=0.16, p<0.05$ ); thus, neuroticism moderates 
TABLE 3 | Results for measurement model.

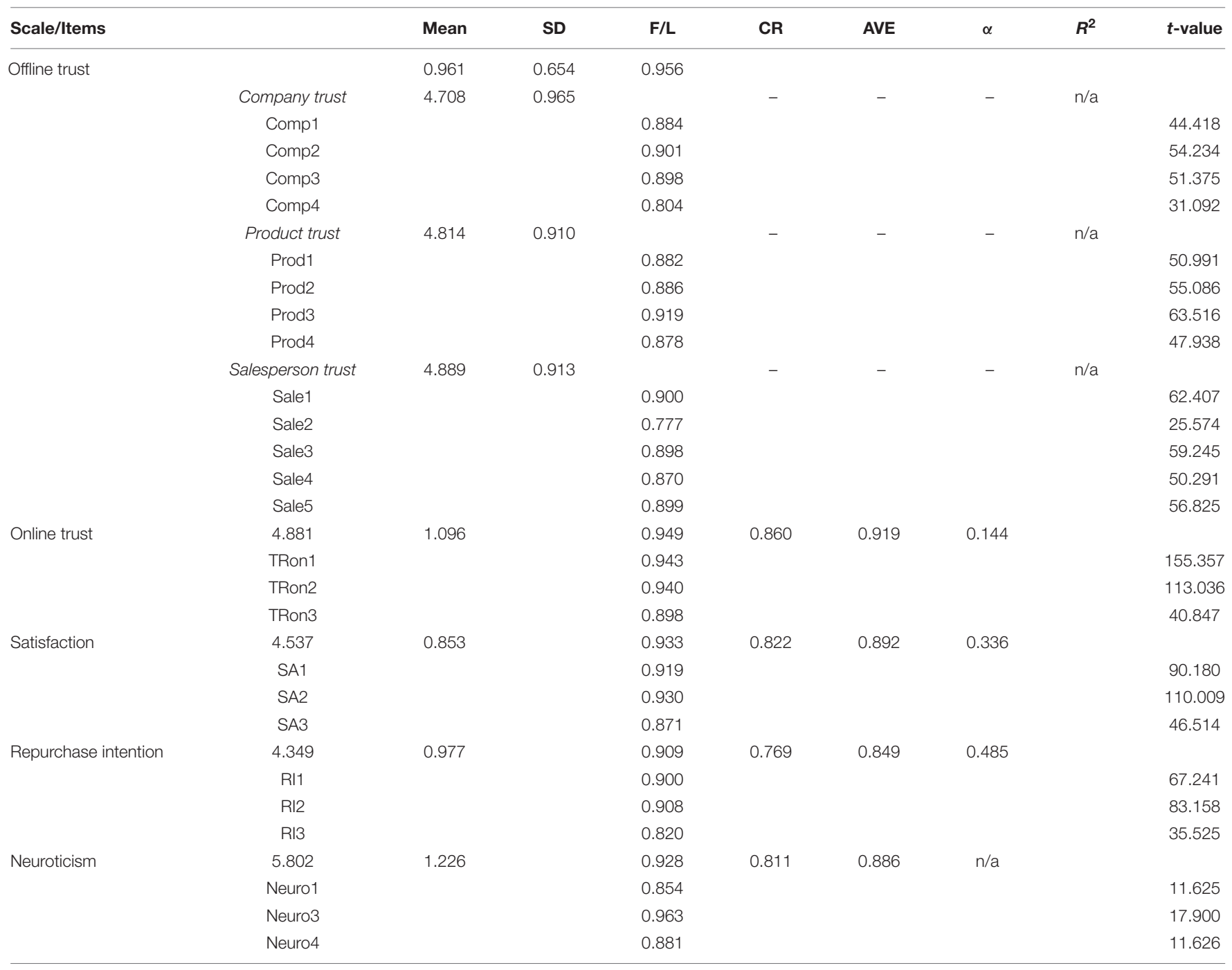

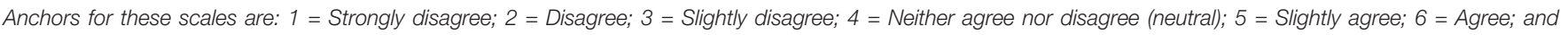
7 = Strongly agree.

the offline-online trust relationship by increasing their degree of online trust. Table 7 below shows the results of our hypothesis tests.

TABLE 4 | Fornell and Larcker criterion for discriminant validity.

\begin{tabular}{llcccccc}
\hline Construct & $\mathbf{1}$ & $\mathbf{2}$ & $\mathbf{3}$ & $\mathbf{4}$ & $\mathbf{5}$ & $\mathbf{6}$ & $\mathbf{7}$ \\
\hline Offline trust & $\begin{array}{l}\text { 1. Company } \\
\text { trust }\end{array}$ & 0.874 & & & & & \\
& $\begin{array}{l}\text { 2. Product trust } \\
\text { 3. Salesman }\end{array}$ & 0.787 & 0.892 & & & & \\
& trust & 0.751 & 0.772 & 0.873 & & & \\
& & & & & & & \\
4. Online trust & 0.341 & 0.343 & 0.359 & 0.927 & & \\
5. Neuroticism & 0.099 & 0.119 & 0.132 & 0.151 & 0.9 & & \\
6. Satisfaction & 0.511 & 0.575 & 0.483 & 0.328 & 0.074 & 0.907 & \\
7. Repurchase & 0.375 & 0.405 & 0.332 & 0.201 & -0.016 & 0.697 & 0.877 \\
intention & & & & & & &
\end{tabular}

\section{Revealing Unobserved Heterogeneity}

Becker et al. (2013) emphasized that unobserved heterogeneity might often conceal the associations between the latent variables. Hence, the latent class methods have been called for calculating the PLS path models by recent researches (Becker et al., 2013; Mourad and Valette-Florence, 2016). In the study, to test Hypothesis 6 for uncovering unobserved heterogeneity in the data sample, we performed the PLSPOS analysis and then re-tested our hypothesis using the segmented data subgroups.

The PLS-POS method is a predictive-oriented segmentation analysis that separates data based on their unobserved heterogeneity. The technique uses a classification approach to allocate observations to clusters deterministically based on data distance (Hair et al., 2017). This part of the analysis addressed our primary purpose, to compare the effects of neuroticism (heterogeneity observed as a variable) in segmented data subgroups (discovered by unobserved heterogeneity analysis 
TABLE 5 | Heterotrait-monotrait ratio (HTMT) for discriminant validity.

\begin{tabular}{lccccc}
\hline Construct & $\mathbf{1}$ & $\mathbf{2}$ & $\mathbf{3}$ & $\mathbf{4}$ & $\mathbf{5}$ \\
\hline 1. Offline trust & & & & & \\
2. Online trust & 0.404 & & & & \\
3. Satisfaction & 0.142 & 0.155 & & & \\
4. Neuroticism & 0.612 & 0.361 & 0.089 & & \\
5. Repurchase intention & 0.443 & 0.222 & 0.072 & 0.797 & \\
\hline
\end{tabular}

Gray box is blank, which is the standard reporting format of PLSSEM HTMT analysis.

using PLS-POS). This analysis demonstrated that the initial results of the hypothesis test could not be accepted at face value.

Although PLS-POS methodology does not offer any indices to select the "best" number of segementations, the techniques relies on the assumption of a distribution-free allocation. On the contrary, the FIMIX approach assumes a multinormal distribution of latent variables, which is not likely to maintain (Mourad and Valette-Florence, 2016). Hence, we applied PLSPOS distribution-free allocation technique.

Since we should identify the number of unknown segmentations, we followed Becker et al. (2013) guidelines to apply this technique using the PLS path model (the global model) for Hypotheses 1 through 5 and calculated the solution for the number of groups $(K)$. We began the POS with two segmentations $(K=2)$ and increased $K$ sequentially until the proportion of one of the groups did not satisfy the prerequisite (10\%). The aggregated $\mathrm{R}^{2}$ of the target construct was chosen in optimization settings, which corresponded to repurchase intention in our model. When the first segmenting process was complete, the original dataset was segmented into two groups $(K=2)$, the first number of predefined groups. Finally, when $K=7$, we finished the iteration because one of the groups failed to meet the criterion with a proportion of $9.4 \%$.
The segmentation with $K=3$ was selected with the optimization measure (i.e., the highest average of $R^{2}$ ). Each subgroup's relative segment sizes of the selected segmentation $(K=3)$ were $23.9 \%(n=97,51.5$ percent male, mean age $=40.3)$, $18.2 \%(n=74,45.9$ percent male, mean age $=41.3)$, and $57.9 \%$ $(n=235,46.4$ percent male, mean age $=40.8)$. See Table 8 for more details. Next, we analyzed the structural models using the dataset of the generated three subgroups from POS. The hypotheses test results of each subgroup differed from the full dataset results $(n=406)$. Moreover, the PLS-POS segmented subgroups' results were quite different (see Table 9 and Figure 2).

In summary, the analysis of the entire dataset $(n=406)$ confirmed all five hypotheses. However, the analysis of the segmented dataset yielded somewhat different findings. For example, in subgroup $1(n=97)$, both Hypothesis 1 (Offline trust $\rightarrow$ Online trust) and Hypothesis 3 (Online trust $\rightarrow$ Satisfaction) were rejected. In subgroup $2(n=74)$, Hypothesis 5 (Offline trust X Neuroticism $\rightarrow$ Online trust) was rejected. In subgroup $3(n=235)$, both Hypothesis 3 (Online trust $\rightarrow$ Satisfaction) and Hypothesis 5 (Offline trust $\mathrm{X}$ neuroticism $\rightarrow$ Online trust) were rejected. These findings suggest that our first study might contain possible Type I errors (Becker et al., 2013). Table 10 shows a comparison of our research models' key findings.

\section{DISCUSSION}

The global model analysis showed that consumers who trust retailers' offline channels also trust their online channels. The result from the global model analysis explained that consumers' trust in offline channels transfers statistically significantly to online channels $(\beta=0.353, p<0.001)$. Moreover, trust transfer influences consumers' perceptions in the trustsatisfaction relation both in offline $(\beta=0.517, p<0.001)$

TABLE 6 | Confidence intervals and VIF.

\begin{tabular}{|c|c|c|c|c|c|c|}
\hline Path & Original sample & Sample mean & $2.5 \%$ & $97.5 \%$ & VIF & $\mathbf{R}^{2}$ \\
\hline Company trust $\rightarrow$ Offline trust & 0.324 & 0.323 & 0.306 & 0.342 & 3.031 & \\
\hline Products trust $\rightarrow$ Offline trust & 0.350 & 0.349 & 0.331 & 0.369 & 3.271 & \\
\hline Salesperson trust $\rightarrow$ Offline trust & 0.410 & 0.409 & 0.390 & 0.427 & 2.858 & \\
\hline Offline trust $\rightarrow$ Online trust & 0.353 & 0.352 & 0.240 & 0.460 & 1.023 & 0.180 \\
\hline Offline trust $\rightarrow$ Satisfaction & 0.517 & 0.516 & 0.419 & 0.604 & 1.168 & 0.336 \\
\hline Online trust $\rightarrow$ Satisfaction & 0.132 & 0.133 & 0.039 & 0.225 & 1.168 & \\
\hline Satisfaction $\rightarrow$ Repurchase intention & 0.697 & 0.696 & 0.624 & 0.761 & 1.000 & 0.485 \\
\hline Neuroticism $\rightarrow$ Online trust & 0.118 & 0.125 & 0.041 & 0.222 & 1.012 & \\
\hline
\end{tabular}

TABLE 7 | Result of hypothesis tests $(N=406)$.

\begin{tabular}{|c|c|c|c|c|c|c|}
\hline Hypothesis & Coefficient & Mean & SD & $t$-values & $P$-values & Results \\
\hline H1. Offline trust $\rightarrow$ Online trust & 0.353 & 0.352 & 0.056 & 6.294 & 0.000 & Accepted \\
\hline H2. Offline trust $\rightarrow$ Satisfaction & 0.517 & 0.516 & 0.047 & 11.010 & 0.000 & Accepted \\
\hline H3. Online trust $\rightarrow$ Satisfaction & 0.132 & 0.133 & 0.048 & 2.754 & 0.006 & Accepted \\
\hline H4. Satisfaction $\rightarrow$ Repurchase intention & 0.697 & 0.696 & 0.035 & 19.878 & 0.000 & Accepted \\
\hline H5. (Offline trust $x$ Neuroticism) $\rightarrow$ Online trust & 0.164 & 0.162 & 0.066 & 2.499 & 0.012 & Accepted \\
\hline
\end{tabular}


TABLE 8 | PLS-POS results for segment retention criteria.

\begin{tabular}{|c|c|c|c|c|c|c|}
\hline $\begin{array}{l}\text { Segment } \\
(K)\end{array}$ & $\begin{array}{c}\text { Offline } \\
\text { trust }\end{array}$ & $\begin{array}{c}\text { Online } \\
\text { trust }\end{array}$ & $\begin{array}{l}\text { Repurchase } \\
\text { intention }\end{array}$ & Satisfaction & $\Sigma R^{2}$ & $\begin{array}{c}\text { Sizes } \\
\text { (relative) }\end{array}$ \\
\hline $\begin{array}{l}\text { Original } \\
R^{2}\end{array}$ & 0.999 & 0.144 & 0.485 & 0.336 & 1.964 & 406 (100\%) \\
\hline$K=2$ & 0.999 & 0.315 & 0.806 & 0.512 & 1.989 & $\begin{array}{c}290 \\
(71.4 \%)\end{array}$ \\
\hline$K=2$ & 0.996 & 0.030 & 0.212 & 0.108 & & $\begin{array}{c}116 \\
(28.6 \%)\end{array}$ \\
\hline$K=3$ & 0.996 & 0.007 & 0.324 & 0.051 & 2.344 & 97 (23.9\%) \\
\hline$K=3$ & 0.992 & 0.876 & 0.615 & 0.827 & & 74 (18.2\%) \\
\hline$K=3$ & 0.998 & 0.141 & 0.721 & 0.484 & & $\begin{array}{c}235 \\
(57.9 \%)\end{array}$ \\
\hline$K=4$ & 0.999 & 0.255 & 0.882 & 0.519 & 2.308 & $\begin{array}{c}226 \\
(55.7 \%)\end{array}$ \\
\hline$K=4$ & 0.993 & 0.105 & 0.046 & 0.248 & & 63 (15.5\%) \\
\hline$K=4$ & 0.994 & 0.734 & 0.730 & 0.397 & & 69 (17\%) \\
\hline$K=4$ & 0.995 & 0.415 & 0.841 & 0.081 & & 48 (11.8\%) \\
\hline$K=5$ & 0.998 & 0.530 & 0.457 & 0.263 & 2.067 & 90 (22\%) \\
\hline$K=5$ & 0.996 & 0.050 & 0.254 & 0.551 & & 73 (18\%) \\
\hline$K=5$ & 0.990 & 0.053 & 0.648 & 0.443 & & 81 (20\%) \\
\hline$K=5$ & 0.998 & 0.088 & 0.643 & 0.335 & & 81 (20\%) \\
\hline$K=5$ & 0.996 & 0.184 & 0.597 & 0.261 & & 81 (20\%) \\
\hline$K=6$ & 0.996 & 0.172 & 0.260 & 0.358 & 1.998 & 68 (16.7\%) \\
\hline$K=6$ & 0.996 & 0.171 & 0.603 & 0.644 & & 67 (16.5\%) \\
\hline$K=6$ & 0.995 & 0.209 & 0.648 & 0.226 & & 68 (16.7\%) \\
\hline$K=6$ & 0.996 & 0.275 & 0.479 & 0.335 & & 69 (17.1\%) \\
\hline$K=6$ & 0.997 & 0.164 & 0.437 & 0.357 & & 66 (16.3\%) \\
\hline$K=6$ & 0.997 & 0.004 & 0.418 & 0.248 & & 68 (16.7\%) \\
\hline$K=7$ & 0.998 & 0.530 & 0.888 & 0.595 & 2.439 & 65 (16.0\%) \\
\hline$K=7$ & 0.998 & 0.357 & 0.772 & 0.825 & & 48 (11.8\%) \\
\hline$K=7$ & 0.996 & 0.342 & 0.641 & 0.381 & & 59 (14.5\%) \\
\hline$K=7$ & 0.997 & 0.014 & 0.861 & 0.531 & & 38 (9.4\%) \\
\hline$K=7$ & 0.995 & 0.155 & 0.411 & 0.352 & & 48 (11.8\%) \\
\hline$K=7$ & 0.998 & 0.502 & 0.693 & 0.165 & & 81 (20.0\%) \\
\hline$K=7$ & 0.993 & 0.140 & 0.675 & 0.271 & & 67 (16.5\%) \\
\hline
\end{tabular}

Notes: The average $R^{2}$ was highest in the seven groups segment solution $(K=7)$, but the smallest group (9.4\%) did not meet the minimum sample size requirement.

and online $(\beta=0.132, p<0.01)$ and satisfaction-loyalty relation positively, $(\beta=0.697, p<0.001)$ and therefore, makes them willing to repurchase. These results are aligned with previous literature that explored offline-online trust transfer
(Badrinarayanan et al., 2012; Bock et al., 2012; Belanche et al., 2014; Lee et al., 2014) and trust-satisfaction-loyalty (i.e., repurchase intention) relationship (Shapiro, 1987; Cyr, 2008; Chen and Chou, 2012; Javed and Wu, 2020; Jung et al., 2020).

Meanwhile, neuroticism, a negative personality trait, was related positively to consumers' trust transfer $(\beta=0.164$, $p<0.05$ ), as Yin et al. (2014) and Zabkar et al. (2017) argued. This result indicates that there will be a higher possibility for neurotic consumers to do trust transferrence. However, in purchasing situations in general, highly neurotic consumers tend to hedge risks and uncertainties about their purchases (Zabkar et al., 2017). Hence, these consumers generally hesitate to transfer from one channel to another channel compared to consumers who are relatively less neurotic. Therefore, this study's outcomes are fascinating and novel because of representing the unusual consequences of neuroticism on trust transfer.

Concerning our exploration of the unobserved heterogeneity that may exist within data samples, which was this study's core research issue (RQ), the results of the global model described earlier showed the potential for biased interpretation. That is, since the global model cannot detect the characteristics that might appear in different segments, we searched the latent groups based on the global model using latent class' techniques, in the study PLS-POS. The results showed three significant segments. It is important to check the improvement of the extracted variance (R2) when the segments are considered (Becker et al., 2013; Arenas-Gaitán et al., 2019). In Table 8, when calculating the model with the complete sample (Global), the aggregated R2 of the model is 1.964 . When we consider each segment $(K)$, the aggregated R2 increases significantly (Originial: 1.964; K2: 1.989; and $K 3: 2.344$ ).

This implication is attributable to the following three significant differences between the model with the entire dataset and models with heterogeneous traits. Firstly, when it comes to the model with the entire dataset, it discovered the phenomenon of trust transfer, while one of the three subgroups did not. Second, the significant influence of trust on satisfaction was not found in two of the three subgroups. Finally, the effect of consumers' neuroticism, a negative personality trait, was not significant in two of the three subgroups during the process of trust transfer.

The implications above imply that revealing consumers' hidden characteristics is fundamental in the field of e-commerce research. Particularly, the results from the sub-models implicitly indicated that neuroticism is unrelated to, or has a weak

TABLE 9 | Results of hypothesis tests for segmented groups.

\begin{tabular}{|c|c|c|c|c|c|c|}
\hline \multirow[t]{2}{*}{ Hypothesis } & \multicolumn{2}{|c|}{ Heterogeneity model $1(N=97)$} & \multicolumn{2}{|c|}{ Heterogeneity model $2(N=74)$} & \multicolumn{2}{|c|}{ Heterogeneity model $3(N=235)$} \\
\hline & Coeff. & $t$-value & Coeff. & $t$-value & Coeff. & $t$-value \\
\hline H1. Offline trust $\rightarrow$ Online trust & -0.106 & 0.758 & 0.937 & $43.631^{\star \star \star}$ & 0.372 & $6.155^{\star \star \star}$ \\
\hline H2. Offline trust $\rightarrow$ Satisfaction & 0.196 & $2.118^{\star}$ & 0.471 & $2.418^{*}$ & 0.638 & $16.253^{\star \star \star}$ \\
\hline H3. Online trust $\rightarrow$ Satisfaction & -0.110 & 1.121 & 0.454 & $2.362^{*}$ & 0.070 & 1.302 \\
\hline H4. Satisfaction $\rightarrow$ Repurchase intention & 0.570 & $7.688^{\star \star \star}$ & 0.784 & $20.085^{\star \star \star}$ & 0.642 & $15.586^{\star \star \star}$ \\
\hline H5. (Offline trust $\times$ Neuroticism) $\rightarrow$ Online trust & 0.325 & $2.008^{\star}$ & 0.040 & 0.927 & 0.053 & 0.726 \\
\hline
\end{tabular}

${ }^{*} p<0.05,{ }^{* * *} p<0.001$. 


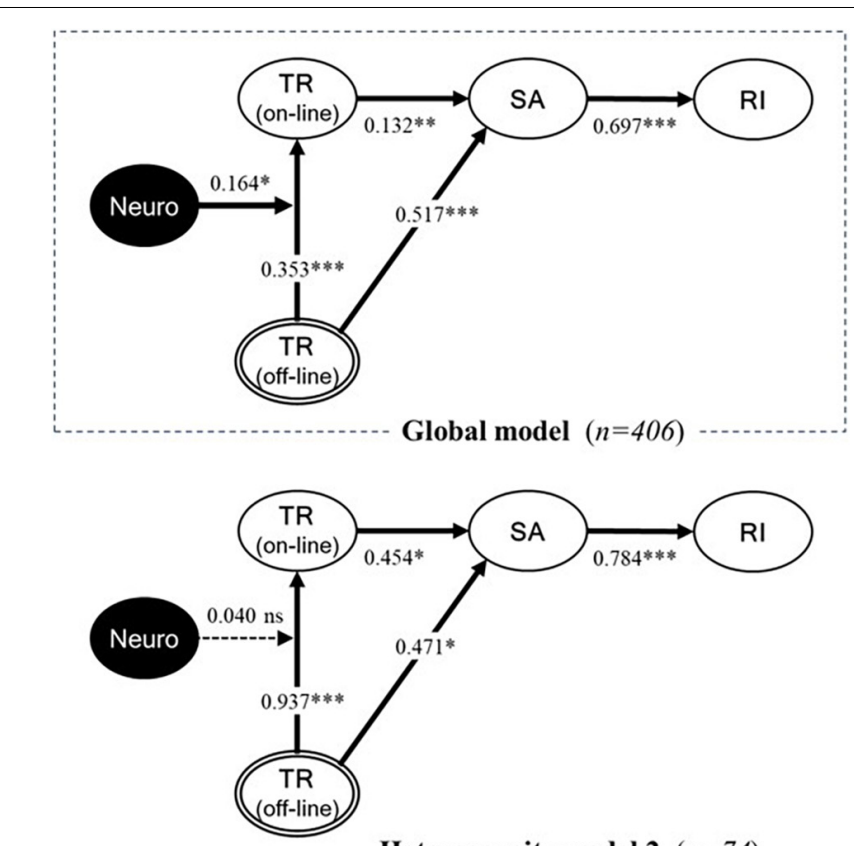

Heterogeneity model $2(n=74)$

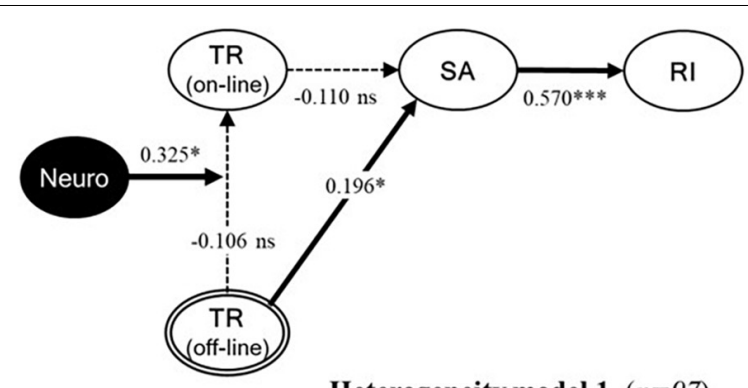

Heterogeneity model $1(n=97)$

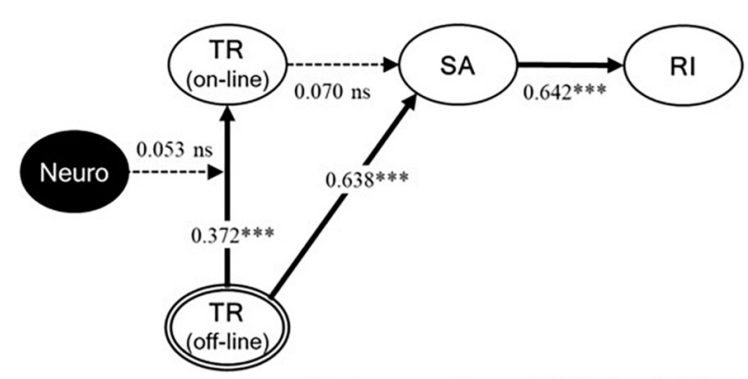

Heterogeneity model $3 \quad(n=235)$

${ }^{*} \mathrm{p}<0.05,{ }^{* *} \mathrm{p}<0.01,{ }^{* * *} \mathrm{p}<0.001 \quad(\mathrm{~ns}=$ not significant at $\mathrm{p}<0.05)$

FIGURE 2 | Proposed research model.

effect on, consumers' trust transfer, although the global model's findings suggested that neuroticism had a significant and explicit moderating impact on consumers' trust. Moreover, neuroticism's influence on online channels after the consumers' trust had transferred exhibited various patterns. Hence, in the relation between the consumers' negative personality trait and trustsatisfaction-loyalty, the main RQ of this study, the following new implications can be derived:

The first heterogeneity model showed that consumers' high neuroticism affects the transition of transfer significantly $(\beta=0.325, p<0.05)$. On the other hand, the second and third heterogeneity models indicated clearly that consumers' weak neuroticism does not affect trust transfer, as the trust does transfer from offline to online channels. These results demonstrate the potential to identify conflicting associations between trust transfer and neuroticism, which explains implicitly that trust in offline channels is

TABLE $\mathbf{1 0}$ | Comparison of key findings.

\begin{tabular}{lcccc} 
Perspectives & Global model & Model 1 & Model 2 & Model 3 \\
\hline 1. Trust transfer & 0 & 0 & $X$ & $O$ \\
$\begin{array}{l}\text { 2. Neuroticism effect on trust } \\
\text { transfer }\end{array}$ & 0 & $X$ & 0 & $X$ \\
3. Effect of online trust on \\
satisfaction after trust transfer
\end{tabular}

more likely to transfer to online channels in e-commerce situations when consumers demonstrate relatively weak neuroticism. As Bove and Mitzifiris (2007) suggested, these findings show that neurotic characteristics of consumers cause unusual behaviors that might not be observed with conventional analysis.

Second, neuroticism's effect demonstrated intriguing patterns in online channels after the trust transfer occurred. In the first heterogeneity model, the trust did not affect satisfaction significantly on the part of the consumer group that was highly neurotic, while the trust-satisfaction relation in the consumer groups that were slightly neurotic exhibited inconsistent patterns in the second $(\beta=0.937, p<0.001)$ and third $(\beta=0.372$, $p<0.001)$ heterogeneity models. These differences in the three models could be excellent supportive evidence of why researchers and field practitioners should take consumers' hidden heterogeneities into account, as Becker et al. (2013) initially suggested. Nonetheless, in all three heterogeneity models, the "offline trust $\rightarrow$ satisfaction $\rightarrow$ repurchase intention" relation was significant, as in the global model that is consistent with former studies (Shapiro, 1987; Cyr, 2008; Chen and Chou, 2012; Javed and $\mathrm{Wu}, 2020$; Jung et al., 2020). Hence, this confirmed ultimately that consumers' loyalty in an e-commerce situation is based firmly on trust in offline channels rather than trust in online channels or consumers' negative personality traits.

In today's extremely competitive e-commerce business environment, it is inevitable for corporations to develop adequate strategies that are adequate for their different types 
of consumers. Hence, based on the outcomes, this research classifies consumers into four distinct brands in the e-commerce context: (1) carnivorous; (2) omnivorous; (3) herbivorous, and (4) frugivorous.

First, carnivorous consumers, who reflect the first heterogeneity model in this research, are a relatively sophisticated and classic type of consumer. These consumers tend to be highly neurotic, which drives them to retain their "offline trust" completely without transfer. Carnivorous consumers' firm preference for "offline territory" primarily is analogous to the attribute of carnivorous animals that have an intense obsession with their hunting ground. For example, this type of consumer is more likely to choose not to purchase if the desired products are unavailable in offline channels. Similarly, carnivorous animals tend to choose to go hungry rather than deviate from their realm. Carnivorous consumers can easily be found in the context of luxury goods retailing because they possess a strong suspicion of replicas that may be sold in online channels.

Secondly, omnivorous consumers, who reflect the second heterogeneity model in this research, are a transitional type of consumer between carnivorous and herbivorous consumers. Omnivorous consumers' tastes are not fastidious. Further, they do not extremely insist on "channel" to confer trust contrasted to carnivorous consumers. Therefore, omnivorous consumers would select any purchase channels with trust as long as they possess what they desire to buy. This behavioral characteristic is quite similar to the traits of omnivorous animals that are not actively selective about their diet as long as they can satisfy their hunger.

Thirdly, herbivorous consumers, who reflect the third heterogeneity model in this research, are a highly prominent type of consumers. These consumers are relatively weakly neurotic about transferring their trust to different channels and have a tendency to employ online and offline channels for different purposes. For example, they make purchase decisions by investigating the actual products in offline channels; however, they proceed with their purchases in one of several different online channels that provide the lowest price. Interestingly, trust is granted only to offline channels, even if herbivorous consumers make actual purchases in online channels. This typical trait of herbivorous consumers is equivalent to the ecological characteristic of herbivorous animals because both search for appropriate online channels and areas to satisfy their specific needs: price, design, and brand for herbivorous consumers and palatable grass for herbivorous animals.

Lastly, frugivorous consumers are a new generation who make purchases and confer trust only in online channels. Similar to carnivorous consumers, frugivorous consumers are highly neurotic, and hence, their trust remains in online channels and does not transfer. Frugivorous consumers have a characteristic similar to frugivorous animals, large primates because both are relatively the latest and most developed types on a classification basis. We have not yet identified this type of consumer in our research; however, if we consider the recent trends in retailing businesses, in which the online
TABLE 11 | Terminology proposal for consumer segmentation in the e-commerce context.

\begin{tabular}{|c|c|c|c|c|}
\hline Term & $\begin{array}{c}\text { Channel } \\
\text { preference }\end{array}$ & Trust & Neuroticism & $\begin{array}{c}\text { Equivalent } \\
\text { model }\end{array}$ \\
\hline $\begin{array}{l}\text { 1. Carnivorous } \\
\text { consumers }\end{array}$ & Offline only & Offline only & Strong & Model 1 \\
\hline $\begin{array}{l}\text { 2. Omnivorous } \\
\text { consumers }\end{array}$ & $\begin{array}{l}\text { Offline and } \\
\text { Online }\end{array}$ & $\begin{array}{c}\text { Offline and } \\
\text { Online }\end{array}$ & Weak & Model 2 \\
\hline $\begin{array}{l}\text { 3. Herbivorous } \\
\text { consumers }\end{array}$ & $\begin{array}{l}\text { Offline and } \\
\text { Online }\end{array}$ & Offline only & Weak & Model 3 \\
\hline $\begin{array}{l}\text { 4. Frugivorous } \\
\text { consumers }\end{array}$ & Online only & Online only & Strong & TBD \\
\hline
\end{tabular}

Model 1 = Heterogeneity model 1, Model 2 = Heterogeneity model 2, and Model 3 = Heterogeneity model 3.

channel's power overwhelming is attributable to offline channels, frugivorous consumers may appear and become a dominant type in the future.

Table 11 below summarizes our proposed consumer classification.

In conclusion, identifying the discrepancies in the global model and the heterogeneity models using unobserved heterogeneity offers deeper reflective concern about trust transfer and negative personality traits in the consumers' loyalty contexts.

\section{CONCLUSION}

The practical implication of the study is that marketing strategies require consumers' undisclosed heterogeneous behavior to be analyzed. In e-commerce purchasing situations, including offline, online, and mobile channels, highly complex factors, such as neuroticism, which may be manifested in unpredictable patterns and may invalidate marketers' efforts, affect consumers' purchase decisions and behaviors. In particular, if we consider the fact that the e-commerce business is intensely competitive today, identifying consumers' hidden traits should not be ignored, as it may affect firms' ability to survive. To provide solutions to unobserved heterogeneity for practitioners in the field of e-commerce, we proposed a novel approach to consumer classification with supplementary terminology: carnivorous, omnivorous, herbivorous, and frugivorous. Hence, firms and managers need to pursue a variety of methods to reveal heterogeneous patterns in their consumers' behavior according to our proposed segmentation of consumers.

In summary, this paper contributes to academia by answering three research questions that this research proposed in the beginning: first, we revealed that there is the influence of trust transfer on consumers' repeat purchase intention; second, neuroticism does moderate offline-online trust transfer relationship in general; third, we proved that ignoring hidden heterogeneity could be a bias by only examining the entire dataset, thus a more robust and detailed statistical analysis, such as PLS-POS approach, would be valuable to find fruitful insights 
in the dataset. These findings would be helpful to researchers and managers in the field of consumer studies.

Our study has the following limitations. First, it revealed unobserved heterogeneous patterns of consumers within the limited frame of trust transfer and trust-satisfaction-loyalty. Future studies need to consider the problem using more research models. Second, our study demonstrated its relevance to trust transfer by considering only a single consumer negative personality trait, neuroticism. Future studies need to find more emotional states. Finally, our study used a specific technique to identify unobserved data heterogeneity. Future research requires consideration of various other analytical methods, such as neural methods that can enhance the furtherance of consumer decision journey (Smidts et al., 2014; Mirica, 2019), to broaden our understanding of the effects of unobserved data heterogeneity.

\section{DATA AVAILABILITY STATEMENT}

The datasets presented in this article are not readily available because the datasets cannot be shared without participant's prior consent. Requests to access the datasets should be directed to kunchanglee@gmail.com.

\section{REFERENCES}

Aluja, A., Rossier, J., Blanch, Á, Blanco, E., Martí-Guiu, M., and Balada, F. (2015). Personality effects and sex differences on the international affective picture system (IAPS): a spanish and swiss study. Pers. Individ. Dif. 77, 143-148. doi: 10.1016/j.paid.2014.12.058

Arenas-Gaitán, J., Ramos, A. F. V., and Peral-Peral, B. (2019). A posteriori segmentation of elderly internet users: applying PLS-POS. Mark. Intell. Plan. doi: 10.1108/MIP-01-2019-0057 Online ahead of print

Badrinarayanan, V., Becerra, E. P., Kim, C.-H., and Madhavaram, S. (2012). Transference and congruence effects on purchase intentions in online stores of multi-channel retailers: initial evidence from the US and South Korea. J. Acad. Mark. Sci. 40, 539-557. doi: 10.1007/s11747-010-0239-9

Bagozzi, R. P., and Yi, Y. (1988). On the evaluation of structural equation models. J. Acad. Mark. Sci. 16, 74-94.

Bai, B., Law, R., and Wen, I. (2008). The impact of website quality on customer satisfaction and purchase intentions: evidence from Chinese online visitors. Int. J. Hosp. Manag. 27, 391-402. doi: 10.1016/j.ijhm.2007.10.008

Barnett, T., Pearson, A. W., Pearson, R., and Kellermanns, F. W. (2015). Fivefactor model personality traits as predictors of perceived and actual usage of technology. Eur. J. Inf. Syst. 24, 374-390. doi: 10.1057/ejis.2014.10

Becker, J.-M., Rai, A., Ringle, C. M., and Völckner, F. (2013). Discovering unobserved heterogeneity in structural equation models to avert validity threats. Mis Q. 37, 665-694. doi: 10.25300/misq/2013/37.3.01

Belanche, D., Casaló, L. V., Flavián, C., and Schepers, J. (2014). Trust transfer in the continued usage of public e-services. Inf. Manage. 51, 627-640. doi: 10.1016/j.im.2014.05.016

Bhattacherjee, A. (2001). Understanding information systems continuance: an expectation-confirmation model. MIS Q. 25, 351-370. doi: 10.2307/3250921

Bock, G.-W., Lee, J., Kuan, H.-H., and Kim, J.-H. (2012). The progression of online trust in the multi-channel retailer context and the role of product uncertainty. Decis. Support Syst. 53, 97-107. doi: 10.1016/j.dss.2011.12.007

Bove, L., and Mitzifiris, B. (2007). Personality traits and the process of store loyalty in a transactional prone context. J. Serv. Mark. 21, 507-519. doi: 10.1108/ 08876040710824861

Bratu, S. (2019). Can social media influencers shape corporate brand reputation? Online followers' trust, value creation, and purchase intentions. Rev. Contemp. Philos. 18, 157-163. doi: 10.22381/rcp18201910

\section{ETHICS STATEMENT}

The studies involving human participants were reviewed and approved by Sungkyunkwan Univetrsity IRB no. 2017-12-011022. The patients/participants provided their written informed consent to participate in this study.

\section{AUTHOR CONTRIBUTIONS}

HJ designed the experiment, collected and analyzed the data, and drafted and revised the manuscript. CK assisted with the experiment, analyzed the data, and drafted and revised the manuscript. JL also assisted with data collection and its analysis. KL supervised the experimental design and the data collection and revised the manuscript. All authors contributed to the article and approved the submitted version.

\section{ACKNOWLEDGMENTS}

We thank Mr. Francis Joseph Costello of the SKK Business School for his helpful comments.

Cao, X., Yu, L., Liu, Z., Gong, M., and Adeel, L. (2018). Understanding mobile payment users' continuance intention: a trust transfer perspective. Int. Res. 28, 456-476. doi: 10.1108/intr-11-2016-0359

Carmines, E. G., and Zeller, R. A. (1979). Reliability and Validity Assessment. Thousand Oaks, CL: Sage publications.

Chen, C.-J., and Hung, S.-W. (2010). To give or to receive? Factors influencing members' knowledge sharing and community promotion in professional virtual communities. Inf. Manage. 47, 226-236. doi: 10.1016/j.im.2010. 03.001

Chen, J., and Shen, X.-L. (2015). Consumers' decisions in social commerce context: an empirical investigation. Decis. Support Syst. 79, 55-64. doi: 10.1016/j.dss. 2015.07.012

Chen, J., Zhang, C., and Xu, Y. (2009). The role of mutual trust in building members' loyalty to a $\mathrm{C} 2 \mathrm{C}$ platform provider. Int. J. Electron. Commer. 14, 147-171. doi: 10.2753/jec1086-4415140105

Chen, X., Huang, Q., Davison, R. M., and Hua, Z. (2015). What drives trust transfer? The moderating roles of seller-specific and general institutional mechanisms. Int. J. Electron. Commer. 20, 261-289. doi: 10.1080/10864415. 2016.1087828

Chen, Y.-T., and Chou, T.-Y. (2012). Exploring the continuance intentions of consumers for $\mathrm{B} 2 \mathrm{C}$ online shopping: perspectives of fairness and trust. Online Inf. Rev. 36, 104-125. doi: 10.1108/1468452121120 9572

Chiu, C.-M., Huang, H.-Y., and Yen, C.-H. (2010). Antecedents of trust in online auctions. Electron. Commer. Res. Appl. 9, 148-159. doi: 10.1016/j.elerap.2009. 04.003

Cyr, D. (2008). Modeling web site design across cultures: relationships to trust, satisfaction, and e-loyalty. J. Manage. Inf. Syst. 24, 47-72. doi: 10.2753/mis07421222240402

Digman, J. M. (1990). Personality structure: emergence of the five-factor model. Annu. Rev. Psychol. 41, 417-440. doi: 10.1146/annurev.ps.41.020190.002221

Dobre, C., and Milovan-Ciuta, A.-M. (2015). Personality influences on online stores customers behavior. Ecoforum J. 4:9.

Doney, P. M., and Cannon, J. P. (1997). An examination of the nature of trust in buyer-seller relationships. J. Mark. 61, 35-51. doi: 10.2307/1251829

Doty, T. J., Japee, S., Ingvar, M., and Ungerleider, L. G. (2013). Fearful face detection sensitivity in healthy adults correlates with anxiety-related traits. Emotion 13:183. doi: 10.1037/a0031373 
Drugău-Constantin, A. L. (2019). Is consumer cognition reducible to neurophysiological functioning? Econ. Manage. Financ. Mark. 14, 9-15. doi: $10.22381 / \mathrm{emfm} 14120191$

Fang, Y.-H., Chiu, C.-M., and Wang, E. T. (2011). Understanding customers' satisfaction and repurchase intentions: an integration of IS success model, trust, and justice. Int. Res. 21, 479-503. doi: 10.1108/10662241111158335

Fornell, C., and Larcker, D. F. (1981). Evaluating structural equation models with unobservable variables and measurement error. J. Mark. Res. 18, 39-50. doi: $10.2307 / 3151312$

Gefen, D., Straub, D., and Boudreau, M.-C. (2000). Structural equation modeling and regression: guidelines for research practice. Commun. Assoc. Inf. Syst. 4:7.

Goldberg, L. R. (1990). An alternative" description of personality": the big-five factor structure. J. Pers. Soc. Psychol. 59:1216. doi: 10.1037/0022-3514.59.6.1216

Hair, J. F. Jr., Sarstedt, M., Matthews, L. M., and Ringle, C. M. (2016). Identifying and treating unobserved heterogeneity with FIMIX-PLS: part I-method. Eur. Bus. Rev. 28, 63-76. doi: 10.1108/ebr-09-2015-0094

Hair, J. F. Jr., Sarstedt, M., Ringle, C. M., and Gudergan, S. P. (2017). Advanced Issues in Partial Least Squares Structural Equation Modeling. Thousand Oaks, CL: Sage Publications.

Henseler, J., Ringle, C. M., and Sarstedt, M. (2015). A new criterion for assessing discriminant validity in variance-based structural equation modeling. J. Acad. Mark. Sci. 43, 115-135. doi: 10.1007/s11747-014-0403-8

Hollowell, J. C., Rowland, Z., Kliestik, T., Kliestikova, J., and Dengov, V. V. (2019). Customer loyalty in the sharing economy platforms: how digital personal reputation and feedback systems facilitate interaction and trust between strangers. J. Self Gov. Manage. Econ. 7, 13-18. doi: 10.22381/jsme7120192

Hong, I. B., and Cho, H. (2011). The impact of consumer trust on attitudinal loyalty and purchase intentions in B2C e-marketplaces: intermediary trust vs. seller trust. Int. J. Inf. Manage. 31, 469-479. doi: 10.1016/j.ijinfomgt.2011. 02.001

Hsu, M.-H., Chang, C.-M., Chu, K.-K., and Lee, Y.-J. (2014). Determinants of repurchase intention in online group-buying: the perspectives of DeLone \& McLean IS success model and trust. Comput. Hum. Behav. 36, 234-245. doi: 10.1016/j.chb.2014.03.065

Javed, M. K., and Wu, M. (2020). Effects of online retailer after delivery services on repurchase intention: an empirical analysis of customers' past experience and future confidence with the retailer. J. Retailing Consum. Serv. 54:101942. doi: 10.1016/j.jretconser.2019.101942

Jeon, H. G., and Lee, K. C. (2016a). A study on the trust tansference and continuance intention to purchase in offline-online multi-channel shopping contexts: emphasis on the moderating effects of neuroticism. Korean Manage. Sci. Rev. 33, 89-115. doi: 10.7737/kmsr.2016.33.2.089

Jeon, H. G., and Lee, K. C. (2016b). Empirical analysis approach to investigating how consumer's continuance intention to use online store is influenced by uncertainty, switching cost, offline trust, and individual negative emotion: emphasis on offline-online multi-channels. J. Korea Contents Assoc. 16, 428439. doi: 10.5392/jkca.2016.16.05.428

Jiménez-Castillo, D., and Sánchez-Fernández, R. (2019). The role of digital influencers in brand recommendation: examining their impact on engagement, expected value and purchase intention. Int. J. Inf. Manage. 49, 366-376. doi: 10.1016/j.ijinfomgt.2019.07.009

Jung, J., Kim, S. J., and Kim, K. H. (2020). Sustainable marketing activities of traditional fashion market and brand loyalty. J. Bus. Res. 120, 294-301. doi: 10.1016/j.jbusres.2020.04.019

Kankanhalli, A., Tan, B. C., and Wei, K.-K. (2005). Contributing knowledge to electronic knowledge repositories: an empirical investigation. MIS Q. 29, 113-143. doi: $10.2307 / 25148670$

Ke, D., Chen, A., and Su, C. (2016). Online trust-building mechanisms for existing brands: the moderating role of the e-business platform certification system. Electron. Commer. Res. 16, 189-216. doi: 10.1007/s10660-016-9217-8

Kim, C., Costello, F. J., and Lee, K. C. (2020). The unobserved heterogeneneous influence of gamification and novelty-seeking traits on consumers' repurchase intention in the omnichannel retailing. Front. Psychol. 11:1664. doi: 10.3389/ fpsyg.2020.01664

Kim, J., and Gupta, P. (2012). Emotional expressions in online user reviews: how they influence consumers' product evaluations. J. Bus. Res. 65, 985-992. doi: 10.1016/j.jbusres.2011.04.013
Kim, K. K., and Prabhakar, B. (2004). Initial trust and the adoption of B2C e-commerce: the case of internet banking. Database Adv. Inf. Syst. 35, 50-64. doi: $10.1145 / 1007965.1007970$

Klinger, U., and Svensson, J. (2018). The end of media logics? On algorithms and agency. New Med. Soc. 20, 4653-4670. doi: 10.1177/1461444818779750

Kuan, H.-H., and Bock, G.-W. (2007). Trust transference in brick and click retailers: an investigation of the before-online-visit phase. Inf. Manage. 44, 175-187. doi: 10.1016/j.im.2006.12.002

Lee, J., Park, D.-H., and Han, I. (2011). The different effects of online consumer reviews on consumers' purchase intentions depending on trust in online shopping malls: an advertising perspective. Int. Res. 21, 187-206. doi: 10.1108/ 10662241111123766

Lee, K. C., Chung, N., and Lee, S. (2011). Exploring the influence of personal schema on trust transfer and switching costs in brick-and-click bookstores. Inf. Manage. 48, 364-370. doi: 10.1016/j.im.2011.09.002

Lee, K. C., Kang, I., and Mcknight, D. H. (2007). Transfer from offline trust to key online perceptions: an empirical study. IEEE Trans. Eng. Manage. 54, 729-741. doi: 10.1109/tem.2007.906851

Lee, K. C., Lee, S., and Hwang, Y. (2014). The impact of hyperlink affordance, psychological reactance, and perceived business tie on trust transfer. Comput. Hum. Behav. 30, 110-120. doi: 10.1016/j.chb.2013.08.003

Lee, M.-C. (2010). Explaining and predicting users' continuance intention toward e-learning: an extension of the expectation-confirmation model. Comput. Educ. 54, 506-516. doi: 10.1016/j.compedu.2009.09.002

Liebana-Cabanillas, F., and Alonso-Dos-Santos, M. (2017). Factors that determine the adoption of Facebook commerce: the moderating effect of age. J. Eng. Technol. Manage. 44, 1-18. doi: 10.1016/j.jengtecman.2017.03.001

Lien, C.-H., Wu, J.-J., Chen, Y.-H., and Wang, C.-J. (2014). Trust transfer and the effect of service quality on trust in the healthcare industry. Manag. Serv. Qual. 24, 399-416. doi: 10.1108/msq-11-2013-0255

Lim, K. H., Sia, C. L., Lee, M. K., and Benbasat, I. (2006). Do I trust you online, and if so, will I buy? An empirical study of two trust-building strategies. J. Manage. Inf. Syst. 23, 233-266. doi: 10.2753/mis0742-1222230210

Lin, J., Lu, Y., Wang, B., and Wei, K. K. (2011). The role of inter-channel trust transfer in establishing mobile commerce trust. Electron. Commer. Res. Appl. 10, 615-625. doi: 10.1016/j.elerap.2011.07.008

Lin, L.-Y. (2010). The relationship of consumer personality trait, brand personality and brand loyalty: an empirical study of toys and video games buyers. J. Prod. Brand Manage. 19, 4-17. doi: 10.1108/10610421011018347

Liu, C.-T., Guo, Y. M., and Lee, C.-H. (2011). The effects of relationship quality and switching barriers on customer loyalty. Int. J. Inf. Manage. 31, 71-79. doi: 10.1016/j.ijinfomgt.2010.05.008

Liu, L., Lee, M. K., Liu, R., and Chen, J. (2018). Trust transfer in social media brand communities: the role of consumer engagement. Int. J. Inf. Manage. 41, 1-13. doi: 10.1016/j.ijinfomgt.2018.02.006

Mark, G., and Ganzach, Y. (2014). Personality and Internet usage: a large-scale representative study of young adults. Comput. Hum. Behav. 36, 274-281. doi: 10.1016/j.chb.2014.03.060

McElroy, J. C., Hendrickson, A. R., Townsend, A. M., and Demarie, S. M. (2007). Dispositional factors in internet use: personality versus cognitive style. MIS Q. 31, 809-820. doi: 10.2307/25148821

Mircicã, N. (2020). Restoring public trust in digital platform operations: machine learning algorithmic structuring of social media content. Rev. Contemp. Philos. 91, 85-91. doi: 10.22381/rcp1920209

Mirica, C.-O. (2019). The behavioral economics of decision making: explaining consumer choice in terms of neural events. Econ. Manage. Financ. Mark. 14, 16-22. doi: 10.22381/emfm14120192

Mourad, S., and Valette-Florence, P. (2016). Improving prediction with POS and PLS consistent estimations: an illustration. J. Bus. Res. 69, 4675-4684. doi: 10.1016/j.jbusres.2016.03.057

Norman, W. T. (1963). Toward an adequate taxonomy of personality attributes: replicated factor structure in peer nomination personality ratings. J. Abnorm. Soc. Psychol. 66:574. doi: 10.1037/h0040291

Odekerken-Schröder, G., De Wulf, K., and Schumacher, P. (2003). Strengthening outcomes of retailer-consumer relationships: the dual impact of relationship marketing tactics and consumer personality. J. Bus. Res. 56, 177-190. doi: 10.1016/s0148-2963(01)00219-3 
Olvet, D. M., and Hajcak, G. (2011). The error-related negativity relates to sadness following mood induction among individuals with high neuroticism. Soc. Cogn. Affect. Neurosci. 7, 289-295. doi: 10.1093/scan/nsr007

Pavlou, P. A., and Gefen, D. (2004). Building effective online marketplaces with institution-based trust. Inf. Syst. Res. 15, 37-59. doi: 10.1287/isre.1040.0015

Perkins, A. M., Arnone, D., Smallwood, J., and Mobbs, D. (2015). Thinking too much: self-generated thought as the engine of neuroticism. Trends Cogn. Sci. 19, 492-498. doi: 10.1016/j.tics.2015.07.003

Pervin, L. A., and John, O. P. (1999). Handbook of Personality: Theory and Research. Amsterdam: Elsevier.

Popescu, G. H., and Ciurlău, F. C. (2019). Making decisions in collaborative consumption: digital trust and reputation systems in the sharing economy. J. Self Gov. Manage. Econ. 7, 7-12. doi: 10.22381/jsme7120191

Rigdon, E. E., Ringle, C. M., and Sarstedt, M. (2010). Structural Modeling of Heterogeneous Data with Partial Least Squares. Bingley: Emerald Group Publishing Limited, 255-296.

Rust, R. T., and Verhoef, P. C. (2005). Optimizing the marketing interventions mix in intermediate-term CRM. Mark. Sci. 24, 477-489. doi: 10.1287/mksc. 1040. 0107

Sánchez-Prieto, J. C., Olmos-Migueláñez, S., and García-Peñalvo, F. J. (2017). MLearning and pre-service teachers: an assessment of the behavioral intention using an expanded TAM model. Comput. Hum. Behav. 72, 644-654. doi: 10.1016/j.chb.2016.09.061

Sarstedt, M., Ringle, C. M., Cheah, J.-H., Ting, H., Moisescu, O. I., and Radomir, L. (2019). Structural model robustness checks in PLS-SEM. Tour. Econ. 26, 531-554. doi: 10.1177/1354816618823921

Sarstedt, M., Schwaiger, M., and Ringle, C. M. (2009). Do we fully understand the critical success factors of customer satisfaction with industrial goods?-extending Festge and Schwaiger's model to account for unobserved heterogeneity. J. Bus. Mark Manage. 3, 185-206. doi: 10.1007/s12087-009-0023-7

Schröder, N., and Hruschka, H. (2017). Comparing alternatives to account for unobserved heterogeneity in direct marketing models. Decis. Support Syst. 103, 24-33. doi: 10.1016/j.dss.2017.08.005

Seppänen, R., Blomqvist, K., and Sundqvist, S. (2007). Measuring interorganizational trust-a critical review of the empirical research in 19902003. Indust. Mark. Manage. 36, 249-265. doi: 10.1016/j.indmarman.2005. 09.003

Shao, W., Ross, M., and Grace, D. (2015). Developing a motivation-based segmentation typology of Facebook users. Mark. Intell. Plan. 33, 1071-1086. doi: 10.1108/mip-01-2014-0014

Shapiro, S. P. (1987). The social control of impersonal trust. Am. J. Sociol. 93, 623-658. doi: 10.1086/228791

Sharif, M. S., Shao, B., Xiao, F., and Saif, M. K. (2014). The impact of psychological factors on consumers trust in adoption of m-commerce. Int. Bus. Res. 7:148.

Shi, S., and Chow, W. S. (2015). Trust development and transfer in social commerce: prior experience as moderator. Indust. Manage. Data Syst. 115, 1182-1203. doi: 10.1108/imds-01-2015-0019

Shiau, W.-L., and Luo, M. M. (2012). Factors affecting online group buying intention and satisfaction: a social exchange theory perspective. Comput. Hum. Behav. 28, 2431-2444. doi: 10.1016/j.chb.2012.07.030

Smidts, A., Hsu, M., Sanfey, A. G., Boksem, M. A., Ebstein, R. B., Huettel, S. A., et al. (2014). Advancing consumer neuroscience. Mark. Lett. 25, 257-267.
Standing, C., Standing, S., and Biermann, S. (2019). The implications of the sharing economy for transport. Transp. Rev. 39, 226-242. doi: 10.1080/01441647.2018. 1450307

Stewart, K. J. (2003). Trust transfer on the world wide web. Organ. Sci. 14, 5-17. doi: 10.1287/orsc.14.1.5.12810

Straub, D., Boudreau, M.-C., and Gefen, D. (2004). Validation guidelines for IS positivist research. Commun. Assoc. Inf. Syst. 13:24.

Svendsen, G. B., Johnsen, J.-A. K., Almås-Sørensen, L., and Vittersø, J. (2013). Personality and technology acceptance: the influence of personality factors on the core constructs of the technology acceptance model. Behav. Inf. Technol. 32, 323-334. doi: 10.1080/0144929x.2011.553740

Teo, T. S., and Yu, Y. (2005). Online buying behavior: a transaction cost economics perspective. Omega 33, 451-465. doi: 10.1016/j.omega.2004.06.002

Trivedi, S. K., and Yadav, M. (2020). Repurchase intentions in Y generation: mediation of trust and e-satisfaction. Mark Intell. Plan. 38, 401-415. doi: 10.1108/mip-02-2019-0072

Wamba, S. F., Bhattacharya, M., Trinchera, L., and Ngai, E. W. (2017). Role of intrinsic and extrinsic factors in user social media acceptance within workspace: assessing unobserved heterogeneity. Int. J. Inf. Manage. 37, 1-13. doi: 10.1016/ j.ijinfomgt.2016.11.004

Wang, N., Shen, X.-L., and Sun, Y. (2013). Transition of electronic word-of-mouth services from web to mobile context: a trust transfer perspective. Decis. Support Syst. 54, 1394-1403. doi: 10.1016/j.dss.2012.12.015

Wu, J.-J., Chen, Y.-H., Chien, S.-H., and Wu, W.-K. (2016). Attachment relationship study of trust and trust transfer. J. Serv. Theory Pract. 26, 681-695. doi: 10.1108/jstp-04-2015-0095

Yang, Q., Huang, L., and Xu, Y. (2008). Role of trust transfer in e-commerce acceptance. Tsinghua Sci. Technol. 13, 279-286. doi: 10.1016/s1007-0214(08) 70045-2

Yang, S., Chen, Y., and Wei, J. (2015). Understanding consumers' web-mobile shopping extension behavior: a trust transfer perspective. J. Comput. Inf. Syst. 55, 78-87. doi: 10.1080/08874417.2015.11645759

Yin, D., Bond, S., and Zhang, H. (2014). Anxious or angry? Effects of discrete emotions on the perceived helpfulness of online reviews. MIS Q. 38, 539-560. doi: $10.25300 / \mathrm{misq} / 2014 / 38.2 .10$

Zabkar, V., Arslanagic-Kalajdzic, M., Diamantopoulos, A., and Florack, A. (2017). Brothers in blood, yet strangers to global brand purchase: a four-country study of the role of consumer personality. J. Bus. Res. 80, 228-235. doi: 10.1016/j. jbusres.2017.06.006

Zhou, T. (2016). Understanding users' switching from online stores to mobile stores. Inf. Dev. 32, 60-69. doi: 10.1177/0266666914526605

Conflict of Interest: The authors declare that the research was conducted in the absence of any commercial or financial relationships that could be construed as a potential conflict of interest.

Copyright (c) 2021 Jeon, Kim, Lee and Lee. This is an open-access article distributed under the terms of the Creative Commons Attribution License (CC BY). The use, distribution or reproduction in other forums is permitted, provided the original author(s) and the copyright owner(s) are credited and that the original publication in this journal is cited, in accordance with accepted academic practice. No use, distribution or reproduction is permitted which does not comply with these terms. 